\title{
AS CONSEQUÊNCIAS DA DIVISÃO DO TRABALHO PARA UM MODO DE VIDA SOCIAL E EMANCIPADO
}

Izauria Zardo $^{1}$

\begin{abstract}
RESUMO
O texto busca fazer uma reflexão sobre a natureza social do ser humano, bem como sua interdependência cada vez maior resultante da divisão do trabalho e fragmentação do conhecimento. Diante desses fatos, procura questionar de que forma ainda é possível falar na emancipação dos indivíduos, conciliando os conhecimentos de interesse comum da sociedade com os conhecimentos especializados de cada área profissional. Tais impasses são notadamente verificáveis ao constatarmos a pobreza e esvaziamento do debate político na esfera pública, o individualismo crescente, a falta de sentido para a própria existência, bem como a naturalização de um determinado modo de vida, em detrimento de outros possíveis. A partir daí, procura abordar qual seria a contribuição da filosofia, numa perspectiva teórica crítica, ao deparar-se com essas questões.
\end{abstract}

Palavras-chave: Divisão do trabalho. Sociedade. Emancipação.

\footnotetext{
${ }^{1}$ Mestranda pelo Programa de Pós-graduação em Filosofia da Universidade Federal de Santa Catarina (UFSC) na área de Ética e Filosofia Política sob orientação do professor Dr. Denilson Luís Werle. Bacharela em filosofia (UFSC/2015). Especialista em Regulação em saúde no SUS (USP/2013). Especialista em Saúde Pública (UFSC/2012). Graduada em enfermagem (UFSC/2007). E-mail: izauria@ yahoo.com.br
} 


\begin{abstract}
The text seeks to reflect on the social nature of the human being as well as their growing interdependence resulting from the division of labor and fragmentation of knowledge. Given these facts, it seeks to question how it is still possible to speak in the emancipation of individuals, combining the knowledge of common interest of society with expertise in each area. Such deadlocks are markedly verifiable when we see poverty and emptying of the political debate in the public sphere, the increasing individualism, lack of meaning in their existence as well as the naturalization of a certain way of life, to the detriment of other possible. From this it seeks to address what is the contribution of philosophy, in a critical theoretical perspective, when faced with these issues.
\end{abstract}

Keywords: Division of labor. Society. Emancipating. 


\section{INTRODUÇÃO}

Quando iniciei meus estudos em filosofia não imaginava as transformações pelas quais passaria ao longo do tempo. Considero-as positivas a maior parte delas, porém, não todas. Uma notável mudança foi a sucessiva quebra de conceitos com consequente ruptura de verdades anteriormente tidas como certas. Esse trabalho de desconstrução de um saber prévio foi salutar, mas trouxe consigo consequências, tais como a perda daquela ingênua vontade de transformar a sociedade em um lugar melhor para todos. Digo ingênua porque era uma motivação muito mais irrefletida, calcada em valores aprendidos na infância, a maioria deles de fundo cristão, do que propriamente senso crítico.

Com o passar do tempo e o acúmulo de conhecimento, somaram-se as incertezas e perdeu-se boa parte do ímpeto transformador, que havia me levado a ingressar no curso. Essa transformação que ocorre com muitos dos estudantes de filosofia é importante, pois convicções cegas podem ser bastante perigosas, mas por outro lado corre-se o risco de cair num relativismo apático, o qual pouco ou nada contribui para a melhoria da vida em comunidade. Não raras vezes a motivação inicial de luta por justiça social e de combate às mazelas da sociedade cede lugar a um discurso especializado e prolixo, que só pode ser compreendido pelos próprios pares, geralmente num circulo restrito à própria academia.

Dito isto pergunto: é conveniente para o todo da sociedade essa maneira de ensinar/aprender filosofia? Ou a filosofia terá sido vítima da especialização e fragmentação do conhecimento? Parece, como na "Dialética do Esclarecimento" de Horkheimer e Adorno, que quando elaboramos esses questionamentos eles se dobram sobre si mesmos. Pois ainda que a academia seja no mais das vezes refém do sistema econômico, ela também é um espaço de resistência, de onde surgem contestações acerca desse sistema econômico e da própria academia. Desta forma a crítica se mantém, como algo inapreensível e ao mesmo tempo ao alcance de todos.

Assim, pretendo abordar no texto a seguir, de que forma percebo a estruturação da sociedade, especialmente no que diz respeito à sociabilidade humana, a divisão do trabalho e suas implicações, bem como conjecturar possíveis alternativas para os problemas apontados. 


\section{A natureza social do ser humano}

Inicialmente vale dizer que a perda de motivação citada no início do texto, a propósito da quebra de algumas certezas, foi sendo gradualmente substituída por uma inquietação diante de fatos muitas vezes tomados como naturais. Fatos estes que envolvem uma sociedade permeada por desigualdades de todos os tipos, mas principalmente de condições materiais e oportunidades.

Talvez essa inquietação seja motivada, mesmo que inconscientemente, por princípios cristãos que permeiam a moralidade de nosso país; ou poderá advir de um conhecimento próprio de causa, pelas adversidades enfrentadas ao longo da vida. Mas independente das causas, opto por atribuí-la à natureza social do ser humano, que nos coloca a todos numa certa condição de igualdade perante a natureza. Igualdade que, quando tolhida gravemente, gera uma reação de desconforto e inquietação.

Entendo como natureza social do ser humano a sua vulnerabilidade biológica ao nascer (com total dependência de outro ser humano), o desenvolvimento de vínculo afetivo e concomitante aquisição e compartilhamento da linguagem. A interdependência e sociabilidade dos seres humanos, portanto, são características antropológicas que podem ser constatadas empiricamente. A formação da identidade de um indivíduo se dá a partir do outro, no processo de socialização. "Vulneráveis nesse sentido, e, portanto, moralmente necessitados de atenção e consideração são os seres que só podem individualizar-se por via da socialização." (HABERMAS, 2000, p.26). ${ }^{2}$

Essas características naturais presentes em nossa espécie nos tornam iguais num certo sentido, no que diz respeito à interdependência e sociabilidade, mas não garante a generalização dessa igualdade num sentido mais amplo, no conjunto dos indivíduos que interagem entre si, em determinado meio onde vivem. Isso porque as diferenças culturais, ambientais e em certa medida genéticas levam cada indivíduo a desenvolver aptidões e experiências próprias, de acordo com cada contexto, tornando-os nesse sentido desiguais.

Temos então que os seres humanos se constituem como indivíduos, com suas peculiaridades e aptidões próprias, mantendo-se, no entanto, ao mesmo tempo membros de uma comunidade que compartilha intersubjetivamente relações de reconhecimento recíproco (HABERMAS, 2000, p.26).

\footnotetext{
${ }^{2}$ Traduzido do espanhol para o português pela autora.
} 
Para Platão, essas diferenças de aptidão e de constituição física de cada indivíduo, aliadas às suas necessidades, seriam a origem da divisão do trabalho. Levando cada um à execução de uma tarefa de acordo com sua natureza. De modo que ao executar apenas uma tarefa, cada trabalhador poderia desempenhá-la com maior perfeição e em menor tempo, devido ao aprimoramento dado pela repetição da atividade. E assim aumentaria a sua produtividade gerando um excedente que poderia ser trocado por outros produtos de sua necessidade, produzidos por outros trabalhadores (PLATÃO, 2008, p.56-57). Ao desempenhar apenas um ofício então, cada indivíduo tornar-se-ia dependente dos demais membros e produtores da comunidade.

Até aqui temos um modo simples de organização da sociedade e divisão do trabalho, com uma economia pautada pelas necessidades primordiais do ser humano. Entretanto, ao longo do tempo a divisão do trabalho evoluiu de tal forma que, nos dias atuais, representa uma limitação para a autonomia e emancipação dos indivíduos. Dito isso, analisarei na sequência, de modo um tanto sucinto, como evoluiu a divisão do trabalho e a produção do conhecimento, bem como suas implicações para o modo de vida social.

\section{A divisão do trabalho e suas consequências}

Ao pesquisar o significado da palavra "trabalho" no dicionário, encontramos a seguinte definição: Trabalho (Do latim tripalium, instrumento de tortura composto de três paus; da ideia de "sofrer" passou-se à de "esforçar-se", "lutar" e, enfïm, "trabalhar".) 1. Atividade humana aplicada à produção, à criação, ao entretenimento. 2. O produto dessa atividade; obra. 3. Atividade profissional remunerada. 4. Exercício de uma atividade profissional; lugar em que essa atividade é exercida. 5. Tarefa a ser executada; serviço (LAROUSSE CULTURAL, 2000, p.879).

Outra definição, um pouco mais ampla, traz o seguinte significado: Trabalho: 1. Ato ou efeito de trabalhar. 2. Exercício material ou intelectual para fazer ou conseguir alguma coisa; ocupação em alguma obra ou ministério. 3. Esforço, labutação, lida, luta. 4. Aplicação da atividade humana a qualquer exercício de caráter físico ou intelectual. 5. Tipo de ação pelo qual o homem atua, de acordo com certas normas sociais, sobre uma matéria, a fim de transformá-la (MICHAELIS). 
Se considerarmos a segunda definição, especialmente os itens 2 e 4, temos que o trabalho acompanha o ser humano desde os tempos mais remotos, podendo mesmo ser naturalizado, uma vez que as atividades necessárias à sua sobrevivência se enquadram na definição. Mas se optamos pela primeira definição nos aproximamos mais da forma atual de trabalho, a qual nem sempre existiu. Nela as atividades passaram a ser desenvolvidas muitas vezes de forma desconectada das suas finalidades. O trabalho passa a ser fragmentado, com funções cada vez mais divididas e especializadas.

Smith, a propósito da divisão do trabalho, sustenta que ela é consequência de uma característica natural dos seres humanos de trocar, permutar ou intercambiar uma coisa pela outra. Como uma "consequência necessária das faculdades de raciocinar e falar". Além disso, a divisão do trabalho seria responsável pelo aumento das forças produtivas de trabalho, o que seria uma vantajosa característica de sociedades mais evoluídas. Mas nessas sociedades, o homem passa a necessitar, a todo o momento, da ajuda e cooperação de grandes multidões, tornando-se nesse sentido dependente dos seus semelhantes. De modo que sem a propensão à barganha, ao escambo e à troca, cada pessoa precisaria conseguir para si mesma tudo o que lhe fosse necessário ou conveniente para a vida que deseja (SMITH, 1996, pp 65-76).

Ainda, segundo o autor, a agricultura não comporta tantas subdivisões do trabalho, nem uma diferenciação tão grande de uma atividade para outra quanto ocorre nas manufaturas. Por este motivo, a agricultura não consegue ter o mesmo aprimoramento das forças produtivas de trabalho que a manufatura, o que a torna menos vantajosa do que esta na produção de riquezas para uma nação (SMITH, 1996, pp 65-76).

Marx, por sua vez, afirma que "a base de toda a divisão do trabalho desenvolvida e mediada pela troca de mercadorias é a separação entre cidade e campo”. Mas há uma diferença essencial entre a divisão de trabalho na sociedade e a divisão de trabalho na oficina, ainda que elas guardem alguma analogia (MARX, 2013, pp. 411-435).

Enquanto na primeira os trabalhadores produzem um produto gradual que depois se transforma em produtos combinados de seus trabalhos específicos, como no caso do criador de gado, do curtidor de peles e do sapateiro, que em conjunto originam os sapatos. $\mathrm{Na}$ divisão manufatureira, em vez disso, o trabalhador parcial não produz um produto gradual que poderá ser comercializado. Somente o produto comum dos trabalhadores parciais converte-se em mercadoria. 
Enquanto a divisão do trabalho na sociedade é mediada pela compra e venda dos produtos de diferentes ramos de trabalho, a conexão dos trabalhadores parciais na manufatura o é pela venda de diferentes forças de trabalho ao mesmo capitalista, que as emprega como força de trabalho combinada (MARX, 2013, p. 429).

Com isso os trabalhadores deixam de ter uma recompensa natural pelo trabalho desenvolvido, passando a produzir apenas certa parte de um todo, que isoladamente não possui valor algum (MARX, 2013, pp. 411-435).

A divisão manufatureira do trabalho é desta forma, uma criação absolutamente específica do modo de produção capitalista. Na qual prevalece a "autoridade incondicional do capitalista sobre homens que constituem meras engrenagens de um mecanismo total que a ele pertence" (MARX, 2013, p. 430).

A partir daí, a divisão do trabalho se intensificou cada vez mais com o surgimento da indústria, das máquinas e do aumento progressivo da tecnologia. Até chegar à situação atual, onde prevalece a superespecialização não apenas da economia, mas também da ciência, das funções políticas, administrativas, judiciárias e até mesmo artísticas. A própria filosofia, que outrora era única, fragmentou-se numa multidão de disciplinas, cada um das quais com seu objeto, seu método, seu espírito (DURKHEIM, 1999, p.02).

Smith descreveu essa transformação da filosofia e da ciência na seguinte passagem:

Com o progresso da sociedade, a filosofia ou pesquisa torna-se, como qualquer ofício, a ocupação principal ou exclusiva de uma categoria específica de pessoas. Como qualquer outro ofício, também esse está subdividido em grande número de setores ou áreas diferentes, cada uma das quais oferece trabalho a uma categoria especial de filósofos; e essa subdivisão do trabalho filosófico, da mesma forma como em qualquer outra ocupação, melhora e aperfeiçoa a destreza e proporciona economia de tempo. Cada indivíduo torna-se mais hábil em seu setor específico, o volume de trabalho produzido é maior, aumentando também consideravelmente o cabedal científico (SMITH, 1996, p. 70).

Mas se para Smith essa divisão era percebida como "progresso da sociedade", tendo, portanto, uma conotação positiva, para Marx a questão assumiria outros contornos.

Ele aponta que tal processo de cisão se inicia na cooperação simples dos trabalhadores individuais, na qual o capitalista representa a unidade e a vontade do corpo social de trabalho. Desenvolve-se na manufatura, que mutila o trabalhador tornando-o um trabalhador parcial. E por fim consuma-se na grande indústria, que separa do trabalho a ciência como potência autônoma de produção e a obriga a servir ao capital (MARX, 2013, pp. 411-435). 
Na mesma direção, Marcuse (1973, p. 154) aponta que o método científico, tendo possibilitado a dominação cada vez mais eficaz da natureza, reuniu tanto os conceitos puros quanto os instrumentos necessários para a dominação cada vez maior do homem sobre o próprio homem. Segundo ele, a tecnologia também garantiria a grande racionalização da não-liberdade do homem, demonstrando a impossibilidade "técnica" da sua autonomia. E essa falta de liberdade ocorreria devido à submissão do homem ao aparato técnico que amplia as comodidades da vida e aumenta a produtividade do trabalho. A racionalidade tecnológica protegeria, desta forma, a legitimidade da dominação capitalista, na medida em que teria se tornado, ela mesma, ideologia.

Para Marcuse, a ciência e a técnica esconderiam deste modo, um projeto a priori de um mundo determinado por interesses de classes, alavancados pela própria situação histórica. Nesses termos, para que a emancipação fosse possível, seria necessário revolucionar a técnica e a ciência, ressuscitando a natureza que outrora foi dominada. Dito de outra forma, em vez de uma natureza explorada, buscar-se-ia uma natureza fraternal (HABERMAS, 2006, pp. 50 -51).

Habermas, no entanto, refere que a evolução técnica obedece à lógica da ação racional teleológica controlada pelo êxito, ou seja, à própria estrutura do trabalho. Logo, não vê a possibilidade de renunciarmos à técnica, "substituindo-a por outra qualitativamente distinta, enquanto não se modificar a natureza humana e enquanto houvermos de manter a nossa vida por meio do trabalho social e com a ajuda dos meios que substituem o trabalho". Mesmo que Marcuse tivesse em mente uma atitude alternativa diante da natureza, disso não se poderia deduzir a ideia de uma nova técnica (HABERMAS, 2006, p. 52).

A subjetividade da natureza não poderia de forma alguma ser livre enquanto a comunicação entre os homens estiver submetida à dominação. Somente quando os homens puderem comunicar-se entre si sem coação e cada um puder reconhecer-se no outro, poderá o gênero humano reconhecer a natureza como um outro sujeito, reconhecer-se nela como noutro sujeito. Assim, a alternativa à técnica existe enquanto interação simbolicamente mediada, a qual difere da ação racional teleológica. Mas isso significa dizer que "os dois projetos são projeções do trabalho e da linguagem, projetos, pois, do gênero humano na sua totalidade, e não de uma época singular, de uma classe determinada ou de uma situação ultrapassável” (HABERMAS, 2006, p. 53). 
Sem entrar no mérito da preponderância de aspectos negativos ou positivos da divisão do trabalho para os diversos autores, passo a expor a seguir minha percepção sobre os fatos na atual conjuntura.

\section{Algumas constatações empíricas}

Que a superespecialização advinda da divisão do trabalho tomou conta de toda a sociedade é algo incontestável, basta observar como se comportam as pessoas e de que forma estão organizadas as instituições, sejam elas públicas ou privadas.

Não é de se admirar, sendo assim, que a grande maioria das pessoas não detenha conhecimento, interesse ou vontade de participar ativamente em áreas que influenciam a vida de todos, como é o caso da política, por exemplo. Esta também se tornou uma função especializada com a divisão do trabalho. De modo que determinados conhecimentos passaram a pertencer a determinadas profissões, permanecendo estranhos entre si.

É muito comum, se nos dispusermos a realizar tal exercício de observação, que os membros de cada categoria profissional, ao encontrarem-se nos seus espaços informais de convívio, conversem e discutam apenas sobre suas áreas de conhecimento, ignorando por completo as demais áreas. Por um lado estão acostumados a pensar de forma especializada, uma vez que assumem desde cedo essa maneira de conceber o mundo e a sociedade, dada pelo próprio sistema educacional. E por outro lado dispõem de pouco tempo livre para dedicar-se a outras áreas do saber, visto que a carga horária de trabalho imposta no sistema capitalista de produção costuma ser extenuante.

Isso sem falar das estratégias utilizadas nos espaços de trabalho para manter os trabalhadores de tal modo treinados e subservientes, que estes passam a defender voluntariamente a ideologia que os explora. Já não conseguem analisar sua própria situação de forma crítica, pois suas funções laborais se desenvolvem mecanicamente, de modo a produzir o máximo possível no menor espaço de tempo, sem perder a qualidade. Um bom exemplo de como funciona a lógica da eficiência produtiva capitalista pode ser encontrado na obra de Frederick Winslow Taylor intitulada "Princípios de administração científica", de 1911, na qual ele desenvolve e defende a utilização de metodologias científicas para o aumento da produtividade pelos trabalhadores. Muitas das estratégias propostas pelo autor ainda são amplamente utilizadas nos dias de hoje e corroboram para o 
quadro de dominação e alienação dos trabalhadores, como se pode constatar nessa passagem:

A mudança da administração empírica para a administração científica envolve, entretanto, não somente estudo da velocidade adequada para realizar o trabalho e remodelação de instrumentos e métodos na fábrica, mas também completa transformação na atitude mental de todos os homens, com relação ao seu trabalho e aos seus patrões (TAYLOR, 1979, p. 95).

Soma-se a isso a Indústria Cultural, já denunciada há tempos por Adorno e Horkheimer, que trata de ocupar todo o tempo livre do trabalhador com uma diversão que mais se parece com o prolongamento do trabalho. A mecanização atingiu tal poderio sobre a pessoa em seu lazer e sobre a sua felicidade, que ela determina tão profundamente a fabricação das mercadorias destinadas à diversão, a ponto de esta pessoa não poder mais perceber outra coisa senão as cópias que reproduzem o próprio processo de trabalho. "Ao processo de trabalho na fábrica e no escritório só se pode escapar adaptando-se a ele durante o ócio. Eis aí a doença incurável de toda diversão”. (ADORNO; HORKHEIMER, 1986, p. 64).

Diante deste cenário, como podemos pretender ainda que as pessoas sejam autônomas? Se até mesmo a filosofia parece ter entrado na lógica do sistema capitalista, tornando-se mais uma engrenagem do mesmo? O que temos em mente quando falamos em autonomia e emancipação dos indivíduos?

Parece-me, a partir da divisão e fragmentação crescente do trabalho, que a autonomia e emancipação foram abaladas em dois sentidos distintos:

1. No sentido material/econômico, na medida em que os trabalhadores tornaram-se interdependentes uns dos outros na produção de bens básicos necessários à própria sobrevivência. Pois nem a agricultura escapou à divisão do trabalho, restando raras propriedades rurais que produzem todo o necessário para a subsistência da própria família E isso tomando a unidade familiar como parâmetro. Se o critério for a autonomia do indivíduo, seu grau de independência material atualmente parece quase nulo; e

2. No que diz respeito à emancipação intelectual, na medida em que a divisão do trabalho proporciona a especialização e divisão do conhecimento em áreas distintas. De modo que cada indivíduo membro de uma sociedade dedica-se a pensar e a conhecer apenas determinado ramo do saber, o qual lhe compete dominar para que possa exercer a parte que lhe cabe na divisão do trabalho total. E assim perdemos a capacidade de observar e 
conhecer o mundo por conta própria. Cada área de conhecimento possui seus especialistas, os quais detém autoridade para tratar dos seus assuntos pertinentes.

Desta forma, cada qual sendo autoridade em determinada fração do conhecimento, precisa aceitar a autoridade dos demais no que tange às demais frações do saber, inclusive nas áreas de interesse comum. Isso leva a um empobrecimento da existência, pois além de impossibilitar de várias formas o diálogo e troca de experiências entre os membros de uma sociedade, impede que a natureza humana se desenvolva em todas as suas potencialidades. Restringe e naturaliza o modo de vida das pessoas a uma condição socioeconômica préestabelecida, como se ela fosse a única possível.

Por fim, esse modo de organização pautado pela superespecialização e divisão do trabalho leva a um adoecimento do corpo social, com domínio de alguns conhecimentos sobre outros, exploração de alguns indivíduos sobre outros e uma desigualdade social alarmante.

Ainda, a desarticulação dos diversos conhecimentos leva os indivíduos a não perceberem a sociedade como um todo e a suportarem isoladamente os problemas que atingem a todos. Problemas que envolvem desde a falta de sentido e motivação para viver, até a privação de bens básicos à vida, passando por situações de extrema violência, insegurança e degradação do meio ambiente. Para citar apenas alguns exemplos.

Sem a perspectiva da emancipação dos indivíduos e a conscientização sobre sua natureza social, não há meios de universalizar o conhecimento que é de interesse comum. E sem universalizar o conhecimento de interesse comum, torna-se difícil que se desenvolva uma sociedade de indivíduos autônomos e conscientes. As falhas se retroalimentam e os danos são compartilhados por todos sem que se consiga pensar coletivamente nas soluções.

A educação, tanto formal quanto informal, parece ser a melhor saída, mas essa esperança se enfraquece tão logo se percebe o papel de mantenedora do status quo por ela desempenhado.

Mas visto que assumir um tom derrotista pode nos levar ao imobilismo, e este em nada contribui na transformação social, opto pelos lampejos de crítica ainda possíveis e pela transformação parcial, gradual da sociedade ao longo do tempo.

Nesse sentido aponto para a concepção habermasiana de que a sociedade é capaz de esclarecer-se no processo de formação da opinião e da vontade, o qual ocorre de modo formal e informal na esfera pública. As argumentações presentes na esfera pública possibilitam o aprendizado a partir de erros explícitos. Os processos de aprendizado têm 
nas argumentações a possibilidade de obtermos conhecimentos teóricos, discernimentos morais, renovação e ampliação da linguagem avaliativa, a superação de autoenganos e dificuldades de entendimento (HABERMAS, 2012, p. 56-57).

Através da ação comunicativa voltada ao entendimento, os indivíduos se reconhecem intersubjetivamente e constituem a esfera pública. Esta, por sua vez, funciona como um sistema de alarme dotado de sensores sensíveis aos problemas comuns da sociedade. No processo democrático de formação da opinião e da vontade, a esfera pública não apenas pode identificar e agrupar os problemas sociais, mas também exercer a pressão necessária para que eles sejam trabalhados pelo complexo parlamentar no sistema político (HABERMAS, 1997, pp. 91-99).

Deste modo poder-se-ia pensar ainda na autonomia dos indivíduos, pelo menos no sentido material. Não pressupondo uma autossuficiência na produção dos bens necessários à vida, mas em vez disso, na distribuição mais justa desses bens produzidos coletivamente. E a partir daí também se poderia pensar a emancipação intelectual, no sentido da tomada de consciência sobre a condição social do ser humano e do compartilhamento dos conhecimentos de interesse comum. Porém, sem a ilusão de que essa transformação ocorra de forma abrupta e totalizante.

Apostemos então num recorte mais amplo da história e fiquemos com aquelas transformações benéficas pelas quais a sociedade já passou e que nos possibilitam algum conforto, a exemplo da Declaração Universal dos Direitos Humanos, da construção do estado de bem-estar social em diversos países, ou ainda do surgimento dos próprios Estados Democráticos de Direito. E que a filosofia mantenha o seu papel nessas transformações, cumprindo a função de instigar o senso crítico, seja ele dentro ou fora da academia.

\section{Considerações finais}

Dadas as análises formuladas e expostas até aqui, algumas considerações ainda podem ser tecidas acerca do tema.

A despeito da sociabilidade humana, presente em toda a espécie como característica natural, muitos fatores impedem atualmente que a sociedade funcione como um todo harmônico. Isso porque a interdependência dos indivíduos, apesar de atingir em maior ou menor grau a todos, é afetada pelas diferenças culturais, materiais, históricas e de 
constituição genética de cada um. Os vínculos afetivos e linguísticos tendem a formar subgrupos dentro da comunidade humana e além disso, alguns artifícios atuam no sentido de escamotear a interdependência entre os indivíduos, como no o caso do dinheiro, que oculta a troca de mercadorias.

Com a divisão do trabalho, inicialmente parece haver uma maior integração dos indivíduos na sociedade, pois que eles se tornariam dependentes uns dos outros na obtenção dos meios de subsistência. Porém, a partir do desenvolvimento da manufatura e o surgimento do sistema capitalista, o trabalho passou a se fragmentar cada vez mais atingindo todas as áreas da sociedade, inclusive a política, ciência, artes e demais conhecimentos de interesse comum das pessoas. Isso fez com que os indivíduos se tornassem engrenagens do sistema econômico, na medida em que desempenham suas funções especializadas e desconectadas do produto final, de forma desarticulada das demais áreas e ignorando quase por completo a interdependência que os unem.

Mas apesar da premente situação que atinge a todos e parece inviabilizar qualquer forma de autonomia e emancipação, ainda resta espaço para a crítica e a resistência, do contrário sequer conseguiríamos formular questionamentos vislumbrando mudanças.

Além disso, a sociabilidade da natureza humana se mantém e pode ser constatada na sua vulnerabilidade biológica, na comunicação voltada ao entendimento e pelo próprio mecanismo de troca de produtos presente na sociedade.

No entanto, a correção dos desvios provocados pelo sistema capitalista na estruturação social, apesar de não ser impossível, requer grandes esforços por parte da sociedade, que envolvem áreas como a política, ética, educação, direito, dentre outras que, em conjunto poderão angariar bons resultados ao longo do tempo.

Quanto à filosofia, é importante que siga elaborando diagnósticos, críticas e apontamentos, contribuindo, desta forma, na construção de uma sociedade mais justa, livre e igualitária para todos.

\section{REFERÊNCIAS}

ADORNO, T.; HORKHEIMER, M. A Indústria Cultural: O Esclarecimento Como Mistificação das Massas. In: Dialética do Esclarecimento. Tradução: Guido Antonio de Almeida. $2^{\mathrm{a}}$ ed. Editora Jorge Zahar. Rio de Janeiro, 1986.

DURKHEIM, E. Da Divisão do Trabalho Social. Tradução: Eduardo Brandão. Editora Martins Fontes. 2 ed. São Paulo, 1999. 
HABERMAS, J. Afectan las objeciones de Hegel a Kant también a la "Ética del Discurso"? In: Aclaraciones a La Ética del Discurso. Traducción e introducción: Manuel Jiménez Redondo. Editorial Trotta. Madri, 2000.

HABERMAS, J. Direito e Democracia - Entre facticidade e validade. Volume II. Tradução: Flávio Beno Siebeneichler (UGF). Rio de Janeiro: Tempo Brasileiro ,1997.

HABERMAS, J. Técnica e ciência como "ideologia". Tradução: Artur Morão. Lisboa /Portugal: Edições 70, 2006.

HABERMAS, J. Teoria do Agir Comunicativo Vol. 1. Tradução: Paulo Astor Soethe. São Paulo: WMF Martins Fontes, 2012.

MARCUSE, H. A ideologia da sociedade industrial - o homem unidimensional. Tradução: Giasone Rebuá. Rio de Janeiro: Zahar Editores, 1973.

MARX, K. Seção IV, capítulo 12 - Divisão do Trabalho e Manufatura. In: O Capital Livro I. Tradução: Rubens Enderle. Editora Boitempo. São Paulo, 2013.

PLATÃO. Livro II. In: A República. Tradução: Pietro Nassetti. $2^{a}$ reimpressão. Editora Martin Claret. São Paulo, 2008.

SMITH, A. A riqueza das nações - Investigação sobre sua natureza a suas causas. Tradução: Luiz João Baraúna. Editora Nova Cultural Ltda. São Paulo, 1996.

TAYLOR, F W. Princípios de administração científica. Tradução: Arlindo Vieira Ramos. Editora Atlas: São Paulo, 1979.

TRABALHO. In: MICHAELIS. Dicionário de Português Online. Disponível em: http://michaelis.uol.com.br/moderno/portugues/index.php?lingua=portuguesportugues\&palavra=trabalho. Acessado em: 08/01/2016.

TRABALHO. In: LAROUSSE CULTURAL. Grande dicionário da língua Portuguesa. Editora Nova Cultural Ltda. São Paulo, 2000. 